\title{
Practices, Policies and Prospects of Social Management in China: A Study Based on "Shidu” Elderly People
}

\author{
Guixia Ma \\ School of Public Affairs \\ University of Science and Technology of China, China
}

Tianming Zhang

Department of Social Work and Social Administration, Faculty of Social Science

University of Hong Kong, China

Ghulam Nabi (Corresponding author)

School of Public Affairs

University of Science and Technology of China, China

Email: ghulam@mail.ustc.edu.cn

Received: February 22, 2016 Accepted: February 26, 2016 Published: March 07, 2016

doi:10.5296/jpag.v6i1.9153 URL: http://dx.doi.org/10.5296/jpag.v6i1.9153

\begin{abstract}
Against the backdrop of reforms in social management, there are more and more families that have lost their only child or whose only child got disabled due to external factors, bringing the group- "Shidu" (Note 1) ${ }^{\mathrm{i}}$ elderly to the focus of the society. When the late years of shidu parents arrive, a series of problems would follow. An investigation shows that shidu parents have diverse needs ranging from financial assistance, physical care, to mental consolation about psychological trauma. To satisfy their holistic needs, social work agencies have developed a " $1+3$ " service mode. Based on an investigation of demands of shidu elderly and the available social management services, this study recommends to the relevant social management units and other social service organizations to establish a comprehensive social management service system for the effective service delivery to these "shidu" elderly known people. The study suggests a comprehensive study from the governmental interventions perspective in this field.
\end{abstract}




\section{$\Lambda$ Macrothink}

Keywords: Shidu elderly citizens, " $1+3$ " service mode, Social work intervention, Social management, Social practices

\section{Introduction}

Against the backdrop of reform in social management, there are more and more families that have lost their only child or whose only child gets disabled, bringing the group - "Shidu" elderly to the focus of China's society. Since 2007 the number of shidu families has soared and so far it has exceeded 1million with an annual increase of 76,000. It is estimated that the total amount of shidu families would reach its peak-2.2 million all over the country in 20382. A report (Note 2) ${ }^{1}$ titled "China's Shidu Families Surpassed 1 m: Shidu Group Swollen" published on Guangzhou Daily on May 9, 2012 aroused attention from the whole nation. Nowadays, shidu is not longer a special phenomenon that falls on a few families; instead, it has become a nation-wide problem. Suffering from traumatic stress, breakdown in social relationship, obstacles in reintegrating themselves into the society, and other problems, shidu parents would encounter plentiful problems when they get old, which thus raises a social concern.

China has issued several policies to provide assistance for shidu families. According to the Population and Family Planning Law of the People's Republic of China (2001), "necessary assistance and support shall be given by local governments to shidu parents who are too old to bear children and would not adopt children after death or disability strike their only child". Nevertheless, there are no specific instructions concerning the "necessary assistant and support", which makes it difficult to enact. Interim Procedures of Poverty-relief Fund for Needy Families under China's One-child Policy published in 2010 stipulates that eligible people "shall receive a monthly allowance no less than 100 yuan from local government until the end of their life", and the amount was raised to 135 yuan in 2011. However, such slim sums are hard to meet basic needs of a shidu family, let alone to make provision for their life after retirement. Judging from contents and implementation effects, though social policies offer certain financial support to shidu families, they do not root out social security problems and psychological predicament confronting shidu families. How to meet the financial and psychological needs of shidu elderly citizens in an effective way? In what aspect can the government improve its existing services? How to provide service for shidu elderly citizens from the angle of social work since they are a marginalized group that draws great attention from the domain of social work? All these questions are worth deliberation and further studies. Based on a research on shidu elderly citizens living in City A, this paper analyzes its " $1+3$ " service mode targeted at shidu parents, and then provides suggestions to improve social work service from the view of empowerment.

\section{Literature Review}

Living conditions and the plight of shidu elderly citizens have aroused wide attention from the academic circle in recent years. Previous studies mainly discussed shidu elderly citizens in the following aspects:

\footnotetext{
${ }^{1}$ China's Shidu Families Exceeded 1m Households: http://news.xinhuanet.com/edu/2012-05/09/c_123097584_5.htm
} 
First, they presented the financial, psychological and basic living needs of shidu elderly citizens and the urgency to solve these problems, as well as put forward some countermeasures. Basically, they stressed concerted efforts from all parties and proposed a service pattern in which the government, communities, social organizations and other interested parties cooperate with each other. Yang (2014) researched into today's embarrassing provision for shidu elderly citizens, and recommended building a multilayer service system for them. Zhou and Rong (2014), with an eye on the difficult life shidu elderly citizens might live, analyzed the mental and physical problems shidu elderly citizens might encounter so as to explore how government management and social resources influence the aged support for shidu elderly citizens in China.

Second, they researched into China's support policies about shidu elderly citizens that are issued by the state and government at different levels, trying to explore a social security system with special attention to shidu elderly. Xie (2013) probed into China's social aid system targeting on shidu group from sustainable livelihoods. He regarded that a shidu elderly aid system should rely on governmental support along with social mutual help, so as to maintain the sustainable livelihoods of shidu group. Revolving around a social security system for the provision of shidu families, Hu and Xing (2013) proposed that China should set up a social security system specially designed for shidu families, which is composed of a diversified social aid system as the fundamental framework, a wide community support network and traditional family support as the auxiliaries.

Third, they dissected shidu policies at specific regions based on practical experience. To tackle the shidu problem, a government-sponsored national fund specially designed for shidu elderly was officially launched in 2007, and related polite projects were put into effect in Chongqing, Jilin and Shanghai. Both achievements and challenges of these pilot projects arouse the interest of a wide range of scholars. Wang and Xie clarified Beijing's shidu elderly social support framework from policy support, financial assistance and psychological health. He reckoned this system on the one hand guarantees that shidu elderly citizens will be "financially supported, nursed well when get ill and pleased psychologically", while on the other hand, it also presents many problems in practical operation.

Four, they paid attention to the reconstruction of shidu elderly citizens' social life from the view of social support. After losing their only child, one-child family members are likely to isolate themselves from people or nearby communities. Fang (2013), based on his empirical study of living condition and social support network of shidu elderly citizens in Hefei, Anhui Province as well as the living condition and needs of shidu elderly citizens in Huainan City, discovered that personal background, the age when losing the only child and social policies are crucial elements that influence the social relation reconstruction of shidu elderly citizens, and that social relations, community recognition, social support and social policies are main factors that lead to the breakdown of shidu elderly citizens' social relations. Then he associated social reconstruction theory from the perspectives of the government, social organizations and shidu elderly citizens, and raised measures to help shidu elderly citizens reconstruct social life and re-fit into communities. 


\section{$\triangle$ Macrothink}

Five, they explored new patterns of social work intervention for shidu elderly from the strength perspective and empowerment. Xiao and Yang (2014) used the strength perspective theory to analyze the aged provision for shidu elderly, in order to unearth problems shidu elderly citizens would encounter in aspects of psychology, economy and daily life. Then they put forward countermeasures to satisfy such needs from the strength perspective. Yao (2012) researched into social work intervention for shidu families, and proposed helping shidu families get rid of mental predicament from both micro and macro perspectives, in attempt to strengthen shidu people's self-efficacy and refine social welfare policies to upscale the social security level for them.

\section{Shidu Elderly Citizens' Needs and Accessible Social Work Service-Case Study of City A}

\subsection{Overview of the Shidu Elderly Service Program in City A}

With recommendation of the Provincial Department of Civil Affairs and approval from the Civil Affairs Bureau, the Provincial Social Work(ers) Association located at City A participated in "Yiyang Home-Eldercare Project for Shidu Families", an exemplary project funded by the central government to encourage social organizations to provide social services. In this project, the Provincial Social Work(ers) Association took the lead and cooperated with the Provincial Family Planning Association and the Provincial Population Foundation. They involved professional social workers to incubate professional social organizations, in the hopes of providing professional, comprehensive, timely and social-wide services for shidu families and exploring innovative and effective social service modes by means of professional social work intervention to meet holistic needs of shidu families.

\subsection{Diversified Social Service Demands of Shidu Elderly Citizens}

According to a questionnaire-based survey about 2,075 shidu elderly citizens in City A, shidu elderly citizens share features as follows in common: first, they are aged people, among whom $90 \%$ are over 50 years old; second, they are in good marital condition, among which $63.8 \%$ get on very well with their spouse; third, their education level is basically low, over $70 \%$ of whom merely graduate from middle school; four, the number of shidu families in urban areas is bigger than the one in rural areas and they are basically living in old towns or old sections of the city; five, a majority of shidu parents live alone. Such characteristics lead to the diversity in social service demand of shidu elderly citizens.

\subsubsection{Great need of financial support}

Financial support is the most fundamental need of shidu people. Over half of respondents in the survey are confronted with financial embarrassment and their financial conditions are showed in Table 1. 
Table 1 Financial Condition of Shidu Elderly Citizens

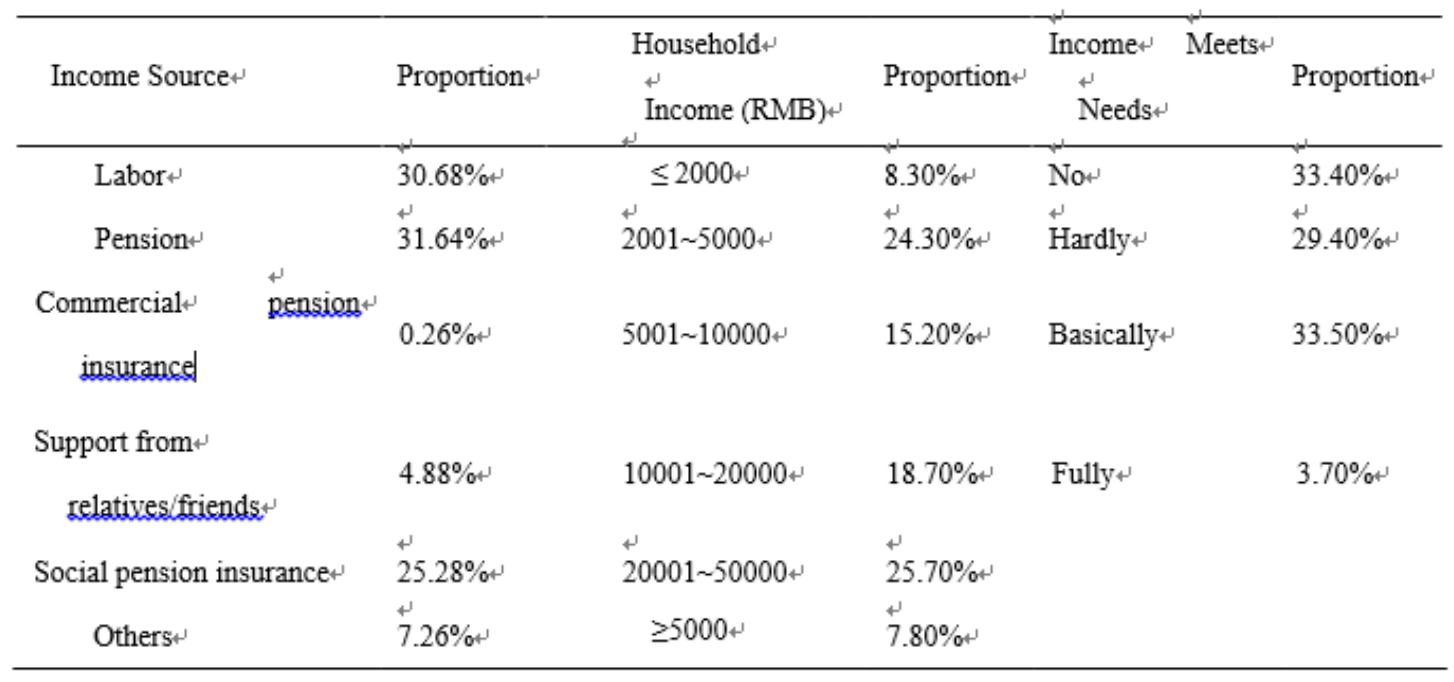

(Please put the date in three-line tables, not screen shot)

According to Table 1, shidu families have various income sources. Approximately $30 \%$ rely on their labor work, while $31.64 \%$ on pension and $25.28 \%$ on social pension insurance. Only $5 \%$ respondents live on support from relatives and friends and very few count on commercial pension insurance. In addition, family planning poverty-relief fund, low-income family allowance and government relief occupy a majority of other income sources. Basically, the income level of shidu elderly citizens is very low. Two thirds of them have a monthly income less than 1,000 yuan and the proportion with an annual income less than 20,000 yuan is up to $66.5 \%$. Their per capital monthly income is no more than 1,000 yuan, showing a general low income level. Furthermore, $8.3 \%$ shidu families have an annual income below 2,000 yuan, which is extremely low. Families with annual income over 20,000 yuan only take up 33.5\% and merely $7.8 \%$ would exceed 50,000 yuan. The income level of shidu elderly citizens depends on their income source and occupation. Judging from "whether income meets daily needs", a large part of shidu elderly citizens fail to meet the ends and $62.8 \%$ have trouble in satisfying their basic needs. $33.50 \%$ basically satisfy their needs and only $3.70 \%$ can fully make the provisions for their own.

\subsubsection{Differentiation in Psychological Care}

Suffering from the lost of only child, shidu parents often take a heavy physical toll. As they get older and older, their physical functions gradually decline. Physical conditions of shidu elderly citizens are different, which makes demand on care at different levels. Details are listed in Table 2. 
Table 2 Physical Conditions of Shidu Elderly Citizens and Their Need of Care

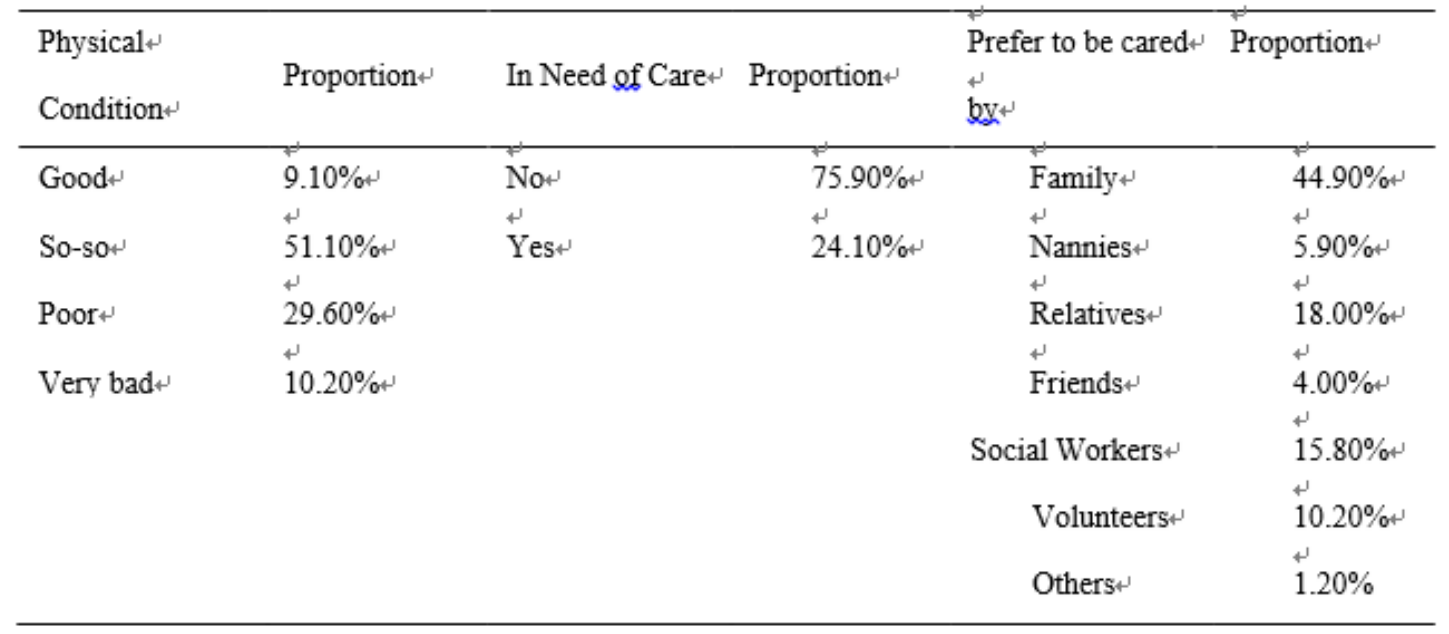

According to Table 2, shidu elderly citizens in good physical condition take up the smallest proportion (only $9.1 \%$ consider they are healthy). Over half think their physical condition is so, while $39.8 \%$ regard they are in "poor" or a "very bad" condition, which makes physical care for shidu elderly citizens a pressing task. Certainly, the psychological resilience and the aging of shidu elderly citizens after suffering crises matter a lot. Nevertheless, most shidu elderly citizens do not think they need special care from others. $75.9 \%$ express that they can take good care of themselves and do not need external care, while $24.1 \%$ impose requirements on care because they are old and waning, or eaten up by diseases. When asked whom they prefer to be cared by, most choose their family members ranging from spouse, siblings, and sons to nephews as well as friends. Only a small part would tend to resort to social workers, neighbors, volunteers, staff members at nursing homes, nannies, etc. It is easily to be seen that family members and relatives are the most favorable people when shidu elderly citizens are in need of care: $62.9 \%$ would expect their family members and relatives to look after them, following by the option of social workers that occupies up $15.8 \%$, volunteer $10.2 \%$ and nannies $5.9 \%$. Merely $4 \%$ respondents prefer friends, which indicates friends are the least favorite alternative.

\subsubsection{Urgent Need to Heal Psychological Trauma}

For many shidu parents, the sadness brought by the death of their only child often develops into a long-lasting depression which is hard to remove. Statistics show that a majority of shidu elderly citizens are easily drowned in negative emotions and psychological status of shidu elderly citizens is displayed as follows. 


\section{Mll Macrothink}

Table 3 Psychological Status of Shidu Elderly Citizens

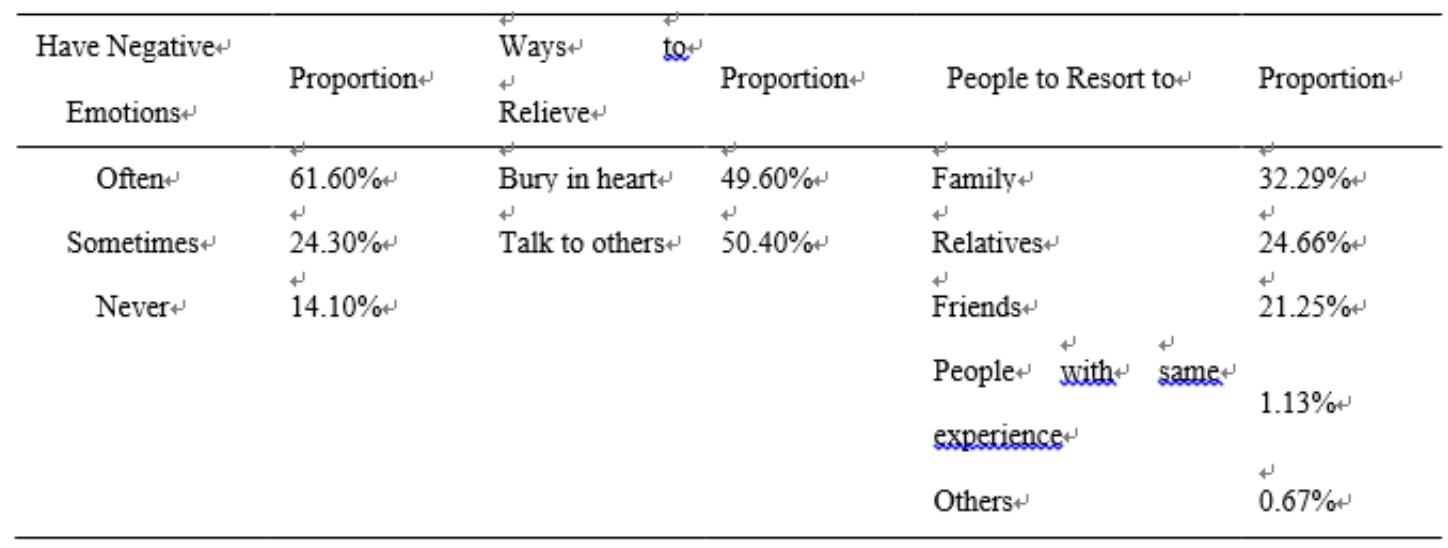

Statistics in Table 3 suggest that over half respondents are often trapped in negative emotions such as depression and disappointment, and $24.3 \%$ sometimes are overwhelmed by negative feelings. Only $14.1 \%$ keep positive towards life. Usually shidu elderly citizens would prefer to "bury in heart" or "talk to others" when they are upset. Proportions of these two groups are very close (49.6\%: 50.4\%). Among all the alternatives for "talk to others", insiders such as family members, relatives and friends are preferable, and they take up $32.29 \%, 24.66 \%$ and $21.25 \%$ respectively. These people always stay with shidu elderly citizens, thus they understand what shidu elderly citizens undergo and might have similar feelings. $11.13 \%$ shidu elderly citizens would rather be with people having the same experience, for they are probably confronted with same predicaments after losing their only child. Under such circumstances, it is easy for them to open heart to each other. In contrast, a few are likely to show their sadness to their colleagues or volunteers and basically they rather hide their sorrow deep in heart. Only few would turn to churches, Buddhist monks and nuns, the residents' committee and the village committee. However, 92\% shidu elderly citizens in the survey do not have religions. Though a majority of people with religions believe they would receive mental consolation to different extents from their gods, only few shidu elderly citizens are able to be comforted spiritually by their religious belief. Suffering from the loss of their single child, most shidu parents would close their heart, refusing to talk to others. Statistics indicate that $24.9 \%$ shidu parents would like to join in Shidu QQ Groups or get-togethers to meet people smoldering with the same pain, while $75.1 \%$ would corner themselves by narrowing their social network and indulging themselves in grief.

On the whole, financial condition of shidu elderly citizens is not good. Some shidu elderly citizens would bear a heavy financial burden due to the expensive medical care for their lost child. Besides, the basic necessities of life (clothing, food, housing, traffic cost and medical care) would all be affected by the rising general price level, especially for those needy families. As a result, the poverty-relief allowance distributed by the government is hard to afford what is available on the market. Therefore it cannot provide a basic financial guarantee for shidu elderly citizens. In addition, the poor physical condition of shidu elderly citizens is another urgent need to be solved. Most respondents state they do not need care, but for those who need, family members, relatives and friends are their favorable options. Nonetheless, as the spouse of shidu elderly citizens gets older and older, they would have an increasing need 


\section{Macrothink}

of social care by domestic nannies, social workers or volunteers. Besides, psychic trauma of shidu elderly citizens requires delicate treatment, which is significant but often neglected. Especially for those likely to isolate themselves from the society and their relatives, and those who tend to bury all their sufferings in heart, timely mental consolation is essential and psychical care would be important. To satisfy the diverse demands of shidu elderly citizens, City A introduced an innovative social service pattern, according to which the government pays for comprehensive shidu eldercare services that are provided by social workers and other service suppliers.

\subsection{Current Social Work Intervention for Shidu Elderly Citizens: "1+3” Service Mode in City} $A$

In China, parents traditionally rely on their children to look after them in old age. However, China's one-child policy makes many families "have no children to rely on". The number of shidu elderly citizens keeps rising in recent years. Nowadays, there is an annual increase of about 240 shidu families in City A, that is, approximately 480 elderly citizens would join the group of shidu people every year. But the scattered and limited nursing homes and spontaneous volunteer activities are far from enough to provide for the expanding group, let alone to help them recover from psychological trauma. In attempt to solve problems such as emotional trauma, isolated social life and inability of self-care, City A determined to construct a shidu elderly support network to provide them with pleasant care and service. Accordingly, in 2012 City A initiated the "Yiyang Home-Eldercare Project for Shidu Families". With communities and professional social workers as the leading roles, a multilayer service network- "professional social workers + family planning specialists + volunteers + professional caregivers for the aged"-was established to bring the professional skills and expertise of social workers into full play. By integrating various kinds of social resources, a package of shidu eldercare services ranging from "visit to special cases", "friendly visit", "accompany and spiritual consolation", "mutual aid team", to "electronic nanny" are designed to meet the diversified needs of shidu elderly citizens. Presently, a comparatively stable " $1+3$ " shidu eldercare service mode has been developed (Figure 1). Professional social workers take the lead, and guide volunteers, family planning specialists and professional caregivers, forming the shidu elderly support system. 


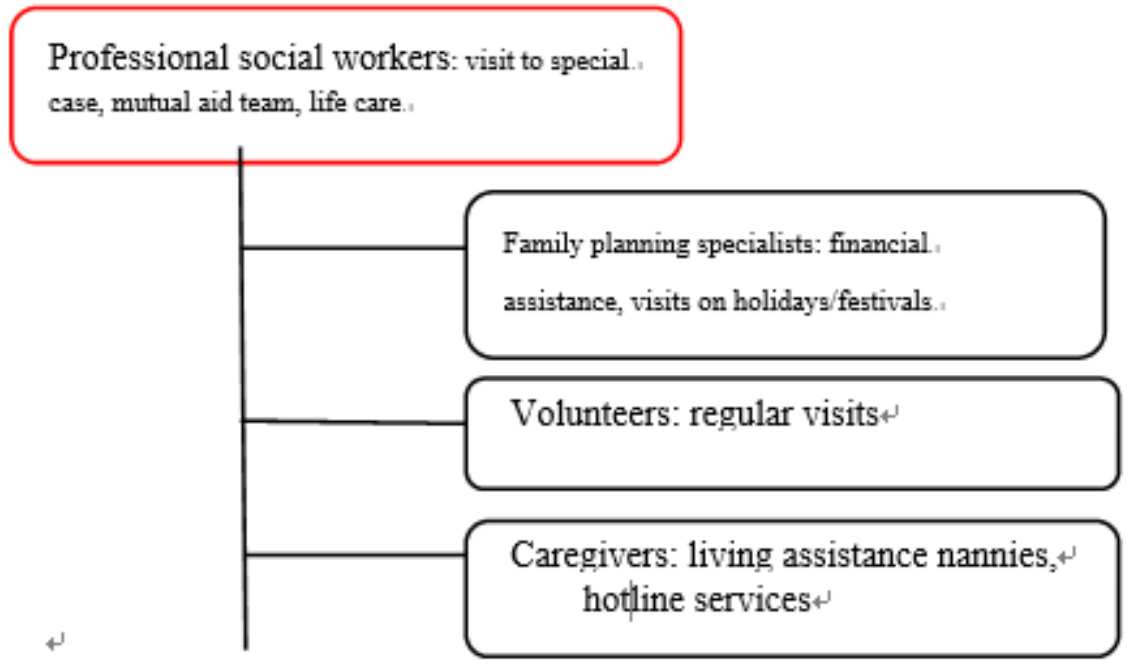

Figure 1. " $1+3$ " shidu eldercare service mode

\subsubsection{Professional Social Workers: Offer Specialized Services}

Playing as the core in the service mode, social workers instill the faith "helping others is helping themselves, helping themselves is helping others" into shidu people's mind throughout their work. They not only help shidu elderly citizens adjust themselves to their normal life, but also help them build a mutual support network. By typical cases studies, team work and community support, social workers factor all kinds of social resources in their service, and instruct volunteers, caregivers and family planning specialists to form a stable and reliable service team.

Professional social workers are mainly devoted to services as follows: first, paying visits to special cases. According to information provided by the Family Planning Department, social workers visit shidu families once at least each month. With this as a routine work, social workers formulate a monthly visit plan and regularly reflect on what they have done and still can do for shidu families. Once they get in touch with shidu families, they immerse themselves in those families to unearth their needs and evaluate their service demands. Then they analyze and classify the emotions, living condition and psychological health of shidu elderly citizens and set up purposeful groups or hold community activities (for adjustment, development, support, mutual aid) in line with professional evaluation methods and the categorized information. By creating opportunities for shidu families to know, get in touch with, adjust to, and fit into the society, they expect to reconnect shidu families with the society, helping them regain their social life and feeling warmth from the society. As for those suffering from emotional hurt, isolation from the society and depression, social workers would provide one-to-one consolation service, timely proffer them care and help them pick up confidence in life and re-set their life objectives. Second, setting up mutual aid teams for people of the similar age. Social workers would establish platforms by means of teams and communities, so as to arrange mutual support activities for shidu elderly citizens. Namely, they closely observe active participants and shidu elderly citizens with special talents or 
interests. Taking advantage of activities to carter to shidu elderly citizens' interests, social workers help shidu elderly citizens build mutual aid teams and instruct them to hold democratic discussions, birthday parties, interest-oriented groups, festivals and other themed-based team/community activities. For instance, life of shidu elderly citizens would be enriched by participating in a "Leyi" Tai Chi Group; resources would be connected to shidu elderly citizens to establish new social network via a "happy dragon boat festival" event. In addition, with strong awareness of allocating and utilizing social resources, social workers involve obliging shidu elderly citizens in charitable social services, removing obstacles for shidu elderly citizens to acclimate themselves into the society again, pick up confidence and re-set their life objectives. Furthermore, social workers would establish a "Yiyang Family QQ Group" for shidu families that are longer for closer relationships with each other, and tightened bonds between shidu elderly citizens and social workers, shidu elderly citizens and shidu elderly citizens via Fetion and WeChat. Third, offering life caring service. By dint of friendly visits, hotline service and other approaches, social workers in collaboration with communities and charitable hospitals regularly monitor diseases of aged people in order to offer shidu elderly citizens medical care and advice in time. For instance, social workers can cooperate with local 3A hospitals to offer body check for shidu elderly citizens and invite healthcare experts to deliver physical healthcare lectures for them. With the concerted efforts of communities and hospitals, social workers offer individualized social service to shidu families such as accompanying and attending to shidu elderly citizens, talking to and comforting shidu elderly citizens, helping shidu elderly citizens vent out sadness, and donating the body of their dead only child according to their living conditions, psychological and physical health with a understanding of their holistic needs and permission.

\subsubsection{Family Planning Specialists: Building Bridges for Shidu Elderly Citizens}

Coordinated with social workers, family planning specialists in communities serve to build up a partnership among social workers, volunteers and shidu families. Besides, family planning specialists analyze the social support system and fundraising regulations to offer allowances to shidu elderly citizens. Currently, City A distributed no less than 3,240 4,080 yuan to each shidu elderly citizen per year. When holidays or festivals come, family planning specialist visit shidu families and bring them necessities. Together with social workers, family planning specialists are devoted to constructing fundraising channels such as network and service station to link communities, enterprises, government sectors and media to contribute to the provision of shidu elderly citizens. For instance, they can publicize their purpose and hold bazaars in communities and initiate campaigns on the Internet to raise fund and collect in-kind relief from all walks of life (including enterprises, individuals and government sectors) to provide financial support and resource replenishment to heal acute diseases and serious diseases for shidu families.

\subsubsection{Volunteers: Assist with Activities/Services}

Volunteers dig out shidu elderly citizens' needs as "friendly visitors" and help social workers organize activities. Professional volunteers (namely, "friendly visitors") are recruited from high education institutions and all walks of life in the society, and then trained, supervised 
and managed to regularly visit shidu people or families (once two weeks) that are probably suffering from emotional pain, psychological loneliness and social isolation according to the shidu service demand evaluation conducted by social workers. Volunteers accompany, comfort and please shidu elderly citizens, providing them emotional support and timely discover what they need. Once detect their service objects are undergoing severe emotional pain, social isolation or depression, volunteers inform professional social workers for special consultation. Those in need of professional eldercare would be looked after by professional caregivers. Presently there are over 230 volunteers in City A's service program. They visit shidu families on weekends or holidays (once every month), during which they cook for shidu elderly citizens, clean their room and talk to them, warming them as family members. According to Table 4, the service program has covered four areas of City A and the service hours of volunteers are long.

Table 4 Volunteer Service

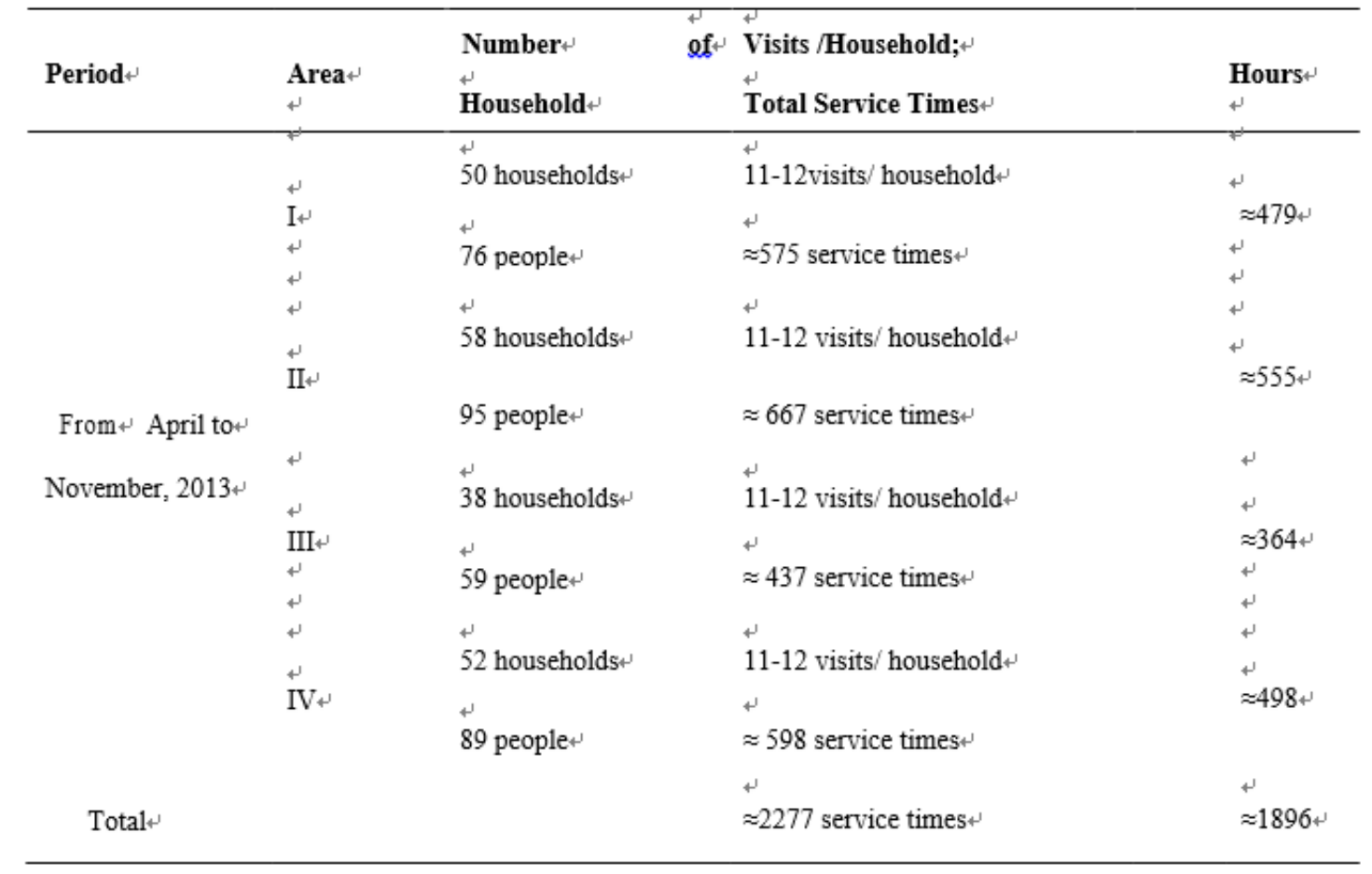

\subsubsection{Professional Caregivers: Offering Comprehensive Home Care Service}

Relying on an "eldercare information management system", City A offers eldercare service voucher worth of 300 yuan per year to each shidu family. It summons caregivers to implement a home care project. Namely, caregivers offer comprehensive home care services ranging from assisted living (housekeeping, accompanying to the hospital, cutting hairs and maintaining good appearance), habilitation service (basic healthcare, massage, body check, etc.), to maintenance of house facilities (water and electricity supply, doors and windows, etc.). Participants in the project are mainly shidu senior citizens living alone, among which $71.8 \%$ are covered by the assisted living, followed by $17.3 \%$ in the maintenance of house facilities. This indicates that assisted living is the paramount need of shidu elderly citizens. Table 5 illustrates how shidu senior citizens use vouchers of the e-nanny service project and 
the total expenditure is 18,965 yuan.

Table 5 Voucher for E-Nanny Service Project

\begin{tabular}{ll}
\hline Month & Fee (Yuan) \\
\hline July, August, & 2540 \\
September & 4925 \\
October & 9255 \\
November & 2245 \\
Total & 18965 \\
\hline
\end{tabular}

This project records information of shidu elderly citizens in the "eldercare information management system" to offer them information network service. Based on this platform, specific call services are provided, so that assisted living service/e-nanny service can be accessed to by shidu senior citizens by related hotlines. Furthermore, a specialized application (a third-party application designed for mobile phones) has been developed and publicized. Composed of four modules, that is, client information, activities issuance, discussion, organization\& administration, this application connect shidu elderly citizens, social workers, volunteers and family planning specialists closely, which boosts the forming of mutual aid teams and the smooth running of their activities, and increases the overall efficiency of the project.

In accordance with the above analysis, the " $1+3$ " shidu eldercare service mode are beneficial for shidu senior citizens to heal their broken social relations and establish a social support system tuned to them. Social supporters, social workers and specialists in communities collaborate with volunteers to remedy the hurt that shidu families suffer from the loss of their single child by acting as their "family members" to "accompany" them both physically and mentally. By this means, the PTSD shidu senior citizens would be placated. Considering the fact that PTSD would affect shidu people to different extents, social workers and volunteers offer "friendly visits", in the hopes of building mutual trust between them and shidu families. Then they would resort to case consultation, mutual aid team and community service to help shidu elderly citizens vent their sadness and depression, open their heart and get rid of negative feelings. Special and urgent needs of shidu families would be satisfied by social workers with the integration of social resources. The "e-nanny service project" would provide assisted living, medical care and certain financial support for shidu elderly citizens whose body functions are gradually degenerating, trying to meet their diverse needs and requirements.

However, there are deficiencies in the " $1+3$ " service mode as well. Firstly, the degree of adhesion between some projects and shidu elderly people are very low. Life care service is restricted to superficial physical healthcare but seldom associated with the real meaning of life. Social workers are frequently rejected when trying to visit shidu families, which blocks 
communication between social workers and their objects. Particularly, when no financial support or in-kind relief is delivered, many shidu elderly citizens refuse to participate in social workers' interviews. Therefore, social workers should uphold the principle of "object -centered" to optimize service projects as well as upgrade their efficacy and the aptitude of social workers organizations. Secondly, service systems are not integrated systematically and comprehensively. A correct service concept has not yet bee instilled in family planning specialists, which makes it significant to change family planning specialists' ingrained belief of "aid and comfort-based care". With respect to the mobility of volunteers, a long-term and stable volunteer team should be established. Economic grant is slim and the source of funds is unstable. Once financial support from the government is withdrew or interrupted, the project has to be halted. Hence social workers should develop fundraising channels to ensure stable funds of services. Currently, social workers are still immature in integrating social resources and how to better correlate different service systems are worth of further discussions.

\section{Reflections and Prospect of Social Work Intervention for Shidu Elderly Citizens from the Angle of Empowerment}

Empowerment has become one of the most widely used theories in today's social work. Its core tenet is to reduce the influence of social and individual hurdles on the execution of existing rights or power, to strengthen people's capacity and confidence of exercising their rights and power, as well as to transfer power from certain groups or individuals to people in need to help them obtain the right to decide and live a life they really want 10 . There are two hypotheses supporting this theory: each man has his potential even if placed in the toughest condition; each man would be helpless to some extent. Solomon (1976) considered such helplessness is stemmed from a person's lack of skills, knowledge or resources as well as his incapacity to control emotions. Thus he fails to play the important social role he is supposed to play well11. For the elderly in need of care pushing to their late years, it is doubtlessly a great shock to loss their only child. Under such a circumstance, they might have no idea how to face such a tragedy, how to apply for government allowance, and how to unleash their negative feelings such as depression and sadness. Many of them even fail to financially support their daily life and break their social connections. All of these would bring them helplessness at different degrees. As far as the author is concerned, social work intervention from the perspective of empowerment should be based on a rational service concept and be provided from three levels: individual, interpersonal and political, in order to establish a multidimensional service system.

\subsection{Normalization-Empowerment in Surroundings of Shidu Elderly Citizens}

Dating back from advocacy of the rights of people with earning disability, normalization appeals to shape an environment for people within a certain organization, where they are empowered a respected social role and a life that would be respected by people outside the organization. Also applicable to groups outside organizations, it aims to change the attitude of the public, service suppliers, service objects and related organizations. For the part of shidu elderly people, normalization is to shape a normal community environment to continue their life. Usually, people would treat shidu elderly with a sympathetic look and regard them as a 
special group in need of aid due to helplessness in many aspects of life. Some organizations even call their visits to shidu elderly citizens on festivals or holidays "warmth delivery", which take it for granted that shidu elderly people are different from other citizens. Some social workers label shidu elderly citizens as the helpless when they publicize services in communities, objectively creating an obstacle for shidu senior citizens to get back to normal community life. In general, social workers should uphold a correct attitude-treating shidu elderly citizens as normal people while providing social work intervention. They should believe shidu elderly people are able to change themselves, live a normal life as others and play their social roles as well as others.

\subsection{Individual Level-Strengthening the Self-Efficacy of Shidu Elderly Citizens}

While providing social work intervention at the individual level, social workers should pay close attention to helping shidu elderly people master daily living skills, improve their self-efficacy, upgrade their self-awareness and reinforce their sense of power. They would make great efforts to make shidu elderly citizens respect, have confident in and reflect on themselves as well as be able to control their feelings. For instance, some shidu elderly citizens often cage themselves in negative emotions such as sadness and depression. Social workers can teach them skills to control emotions or get rid of negative feelings, showing them that they can face life positively. In our daily life, some shidu elderly people might find it hard to live a normal life after losing their single child. Social workers can help them get back to their previous life channel, showing them their power to make a change and increasing their self-efficacy. Besides, social workers can keep shidu elderly citizens away from sadness by life education from the perspective of life care, so that they can look at life in a better way and strengthen their self-awareness. The focus of empowerment at the individual level is to increase individuals' living skills and power to change the social environment.

\subsection{Interpersonal Level-Reconstructing the Social Network for Shidu Elderly Citizens}

With regard to social work intervention at the interpersonal level, social workers help shidu elderly citizens establish a social network by means of mutual interaction with others, in attempt to heal their broken social relations, provide them certain social resources and social capital to improve their living environment and working environment. According to previous services, though social workers emphasize the reconstruction of social network of shidu elderly people and facilitate interaction between shidu people in the form of team activities, shidu people's relations with others are limited to team works. That is to say, once team activities are finished, their interaction would come to the end. In this regard, a solid social connection network is hard to build. From the perspective of empowerment, social workers push self-service and participant of service objects, so that shidu families sharing same problems would group together to support each other, establish a mutual-aid organization in which they share successful experience to overcome obstacles and encourage others, forming a long-lasting and effective self-service and mutual-aid pattern. Shidu elderly also express their individual needs during cooperative work. Furthermore, making the most of existing volunteer resources, a professional volunteer team is founded to expand the service coverage 
of volunteer service: shifting the traditional donation (money and materials) to concerning the overall change in the life of shidu elderly citizens. With a close connection between volunteers and potential shidu elderly citizens living alone, volunteers will have a better understanding of their needs and can speak for them, advocate the general public to care them, integrate a wider range of social resources and reconstruct the social connection network for them. The aim of empowerment at the interpersonal level is to help shidu elderly citizens improve themselves and dispense with the influence of their disadvantages by interaction with others.

\subsection{Political Level-Making Social Policies to Protect Rights of Shidu Elderly Citizens}

While proving social work intervention at the political level, social workers attach great importance to the influence of social policies on shidu people, devoting to help shidu people voice their interest appeals and participate in the redistribution of social resources. Nowadays, there is one only social policy tuned to shidu elderly citizens issued by China's central government, namely, the Interim Procedures of Poverty-relief Fund for Needy Families under China's One-child Policy". Even the Law of the People's Republic of China on Protection of the Rights and Interests of the Elderly pays no extra attention to shidu elderly citizens. According to the Interim Procedure, each shidu family member in urban areas is eligible to receive a monthly allowance from 270 to 340 yuan from the government while each eligible person in rural areas is entitled with 150 170 yuan per month. The amount of allowance varies with the income gap between urban areas and rural areas. In conformity with the national standard, Beijing grants each eligible citizen 340 yuan per month and 500 yuan every month for people living under the minimum living standard. The allowance distributed to shidu families is much lower than the one for families living under the minimum living standard, thus it is hard to guarantee the normal living standard of shidu families. In contrast, each shidu elderly citizen is given a special fund valued at 3,120yuan per year in Chongqing and altogether 6,240 yuan for each shidu family, which distinctly exceeds the national standard. On the basis of the national standard, City A gave an extra amount of 420 yuan per year to each eligible shidu person, so that each shidu family member will receive an allowance no less than 4,500 yuan each year. However, compared to the sustainable allowance (460 yuan per person per month) for families living under minimum living standard, the allowance given to shidu families is still low, which is far from enough to guarantee the basic needs of shidu families. Thus in the political level of empowerment, social workers should advocate that the government pays special attention to shidu elderly citizens when making policies. New social policies should not only cover their basic needs for existence, but also provide comprehensive support for them. Policy makers should formulate a comprehensive package of service-oriented policies to protect the rights and interests of shidu elderly citizens by learning from social policies designed for "three-without persons" (literately means "people without source of income, without labor capacity and without legal guidance") in urban areas as well as rules and regulations regarding five guarantees family (the aged, the infirm, old widows and orphans) taken care of by the people's communes in rural areas in five ways (food, clothing, medical care, housing and burial expenses). The study suggests a comprehensive study from the governmental 


\section{Macrothink \\ Journal of Public Administration and Governance \\ ISSN 2161-7104 \\ 2016, Vol. 6, No. 1}

interventions perspective in this field.

\section{References}

1. Yang, Z. Y. (2014). Provision for China's shidu elderly citizens and possible supports. Social Work, 1, 135-140.

(Please do not number the references. All references should be follow the format of the first reference and the last two ones)

2. Zhou, Y., \& Rong, R.J. (2014). Problems and measures of provision guarantee for China's shidu elderly citizens. Human Resource Management, (3), 162-163.

3. Xie, Y.C., Huang, W.D., \& Wang, M.F. (2013). Social aid system for shidu people from perspective of sustainable livelihoods. Social Security Studies, (1), 72-79.

4. Hu, D.Q., \& Xing, Q.S. (2013). Construction of social security system targeting at provision for shidu families. Sanxia Forum (Sanxia Literature-theoretical volume), (1), 76-79.

5. Wang, M.F., \&Xie, Y.C. (2013). Social security for shidu people: A case study of Beijing. Lanzhou Academic Journal, (7), 91-96.

6. Fang, S.G. (2013). Social isolation and social support: Reconstruction of social relationship of shidu elderly citizens. Population and Development, (5), 89-94.

7. Fang. S.G. (2013). Social isolation, social support and social acclimation: Reconstruction of social life for shidu elderly citizens. Journal of Yunnan Normal University (Humanities and Social Sciences), (9), 105-112.

8. Xiao, Y., \&Yang, G.H. (2014). Difficulties in provision for shidu elderly citizens and related countermeasures from strength perspective. Population and Development, (1), 107-112.

9. Yao, J.D.(2012). An analysis of shidu families based on function of social work. Social Work, (10), 24-27.

10. Payne, M. (2005). Modern social work theory (3rd edition). In Y. L. Feng \& P. F. Ye (Trans.). Beijing: China Renmin University Press.

11. Solomon, B. (1976). Black empowerment: Social work in oppressed community. Columbia University Press.

\section{Copyright Disclaimer}

Copyright for this article is retained by the author(s), with first publication rights granted to the journal.

This is an open-access article distributed under the terms and conditions of the Creative Commons Attribution license (http://creativecommons.org/licenses/by/3.0/). 
${ }^{\text {i }}$ Shidu elderly people refers to aged parents 60 or above, who have lost their only child. 